\title{
Las afueras de la justicia
}

\section{The Outskirts of Justice}

Óscar Ortega Ruiz

Sección Técnica de Conservación de la Gerencia Municipal de urbanismo de Málaga

\section{Resumen}

El presente trabajo pretende ser una reflexión política acerca de la importancia de la gestión del territorio, entendido como escenario de convivencia humana. A través del análisis de aportaciones de autores de relevancia social y filosófica, se destaca la mutua implicación que existe entre las diversas concepciones de la justicia y su plasmación en realidades espaciales. Se advierte acerca de la puesta en práctica de determinados prejuicios ideológicos, provenientes de una concepción coactiva del derecho, en nuestro modo contemporáneo de concebir la ciudad, lo cual acarrea importantes disfunciones sociales, incluyendo la perpetuación de situaciones de marginalidad, desigualdad y exclusión. Para solventar estas lacras, se propone la puesta en práctica de estrategias de diálogo social desde posiciones libres de presupuestos jerárquicos.

Palabras clave: justicia, ciudad, disciplina, control, convivencia.

\begin{abstract}
The present work aims to be a political reflection about the importance of the management of territory, understood as scenario of human coexistence. Through the analysis of contributions from authors of social and philosophical relevance, it stands the mutual involvement among the diverse conceptions of Justice and
\end{abstract}


its manifestations in spatial realities. It warns about the implementation of certain ideological prejudices from a coercive concept of law, in the way we currently conceive the city, which carries significant social dysfunctions, including the perpetuation of marginality, inequality and exclusion. To solve these scourges, it proposes the implementation of strategies of social dialogue from positions free of hierarchical prejudices.

Keywords: Justice, City, Discipline, Control, Coexistence.

Ciudad y utopía

Con la Ética Nicomaquea, Aristóteles aborda la investigación de la virtud y la justicia, que identifica con la vida buena (Aristóteles, 2001). En su continuación, la Politeia, el estagirita lleva ahora estas reflexiones al ámbito de las leyes y las instituciones políticas de la polis. Para él, la ciudad no es únicamente una colectividad emplazada en un lugar, cuyo fin es evitar la injusticia mutua y facilitar el intercambio, sino una comunidad humana con la meta de vivir bien, de conseguir la vida perfecta y suficiente (Aristóteles 1994). Varios filósofos utopistas de la Edad Moderna -Tomás Moro, Francis Bacon o Tommaso Campanella, por citar algunos- se sirvieron de descripciones de ciudades idealizadas para proponer modelos de estados regidos por la justicia y el progreso. La ciudad, así entendida, aspiraría a instituirse como el artefacto social, ligado a un territorio, donde los hombres se relacionan con los hombres guiados por la inteligencia y la moralidad: el alma de la existencia humana.

Aún para autores contemporáneos como Hans Jonas, toda la ética que nos ha sido transmitida habita en este marco intrahumano, el ámbito físico de convivencia ejemplificado por la ciudad, y se ajusta a las medidas de la acción condicionada por él (Jonas, 2008: 28). La ratio essendi de la convivencia en sociedad consistiría en que fuese posible la vida humana, o mejor aún, que 
fuese posible una vida buena. De esto debe cuidarse el verdadero gobernante (Jonas, 2008: 177). Sin embargo, observamos que, en muchas ocasiones, la realidad de la ciudad y la sociabilización contemporánea de ámbitos físicos y territoriales, distan mucho de acercarnos a estas visiones optimistas. Por el contrario, se constata la existencia de un amplio espectro de patologías sociales cuyo análisis resulta indesligable de nuestra comprensión como seres proyectados espacialmente.

\section{Concepto de heterotopía}

Son muchos los ejemplos que muestran un uso perturbador de los espacios físicos de convivencia. En una conferencia pronunciada en el Círculo de Estudios Arquitectónicos de París en 1967, Michel Foucault introduce el concepto de heterotopía para denominar a aquellos espacios donde se ubica a los individuos cuyo comportamiento está "desviado" con respecto a la media o a la norma exigida. Como ejemplo, Foucault cita las casas de reposo, los manicomios, las prisiones, los geriátricos y hasta los cementerios. Con la vista puesta en nuestra realidad contemporánea, nosotros podríamos añadir las clínicas de desintoxicación, los centros de internamiento para inmigrantes, los campos para refugiados, los polígonos industriales donde se ejerce la prostitución, los barrios marginales, donde a veces llegan los habitantes de las zonas pudientes para abastecerse de droga, etc. Es como si a la periferia de la ciudad le correspondiera una periferia de la justicia, unas modernas leproserías donde se agrupan los sujetos considerados indignos de convivir con la mayoría. Las heterotopías cumplirían, entonces, la función de alejar de la ciudadanía hegemónica la cara desagradable de la realidad para crear la ficción de un mundo edulcorado. Estos lugares podrían integrarse en la interpretación que Derrida tiene del término platónico de khôra $(\chi \omega \rho \alpha)$, aparecido 
en el diálogo Timeo: un lugar a medio camino entre lo sensible y lo inteligible; entre el ente y el ser; entre tener lugar y tomar un lugar; una hendidura en la que todo vendría a la vez a tomar sitio y reflejarse; el lugar político, por oposición al espacio abstracto (Derrida, 1995). Las heterotopías son un lugar, pero constituyen también un concepto que ilustra el fracaso del ideal utópico de vida perfecta en la ciudad, que se ha visto transformado en distopía.

\section{El derecho coactivo}

Se hace necesaria la búsqueda de respuestas acerca del origen y alcance conceptual de estos lugares distópicos, donde se emplaza la injusticia. Foucault señala que la prisión, la heterotopía por excelencia, nunca perteneció al proyecto de los pensadores reformistas del siglo XVIII como Beccaria o Bentham, entre otros. Las penas para delincuentes sopesadas en dichos debates teóricos consistían más bien en acciones como la deportación, exclusión, trabajos forzados o muerte. La prisión, la heterotopía por excelencia, no pertenece al proyecto de reforma de la penalidad de dicha época. Sin embargo, surge con fuerza a comienzos del siglo XIX como una institución que se impone de hecho, casi sin justificación teórica. Para Foucault, constituye el imperativo de una sociedad que ha tomado una orientación marcadamente disciplinaria (Foucault, 1986: 91-96).

Podemos remitirnos a ciertas reflexiones del pensador francés Emil Durkheim para intentar comprender el origen antropológico del castigo disciplinario. Para él, el fundamento de la autoridad moral de las normas sociales tuvo un origen sagrado. El delito primordial sería el sacrilegio, la profanación de lo santo. La represión del sacrilegio constituye una manifestación de consternación y terror ante las fatales consecuencias que pudiese acarrear. El castigo constituye, así, la otra cara de lo adoración de lo sagrado: un ri- 
tual que restablece el orden perturbado. El castigo es considerado, pues, como una expiación orquestada socialmente (Durkheim, 1978: 68).

Sea como ejercicio más o menos gratuito de disciplina o como reflejo atávico de expiación, lo cierto es que la concepción de una penalidad coactiva y sin pretensiones reformadoras se encuentra sólida e incontestablemente asentada en la sociedad del XIX. Remontándose a los inicios de la tradición moderna del derecho para intentar responder la pregunta de si puede el contrato social ligar a las partes en ausencia de fundamentos sagrados, Habermas señala que, de Hobbes a Max Weber, la respuesta recurrente que se ha venido dando a esta cuestión es que el derecho moderno es, justamente, un derecho coactivo. La interiorización paulatina de la moral va acompañada en la conciencia social de una complementaria metamorfosis del derecho en un poder impuesto desde fuera, basado en la autoridad del estado y respaldado por las sanciones del aparato público (Habermas, 2003b: 115).

La prisión constituye, para Foucault, el modelo de este tipo de sociedad transformada en amenaza. La forma ejemplar, simbólica, de todas las demás instituciones de secuestro del siglo XIX. Esa es la explicación de su éxito que, con muchos inconvenientes, se impuso al derecho penal y al ideal ilustrado de educación y reinserción social. La necesidad de control a la que responde había surgido con el auge de nuevas formas de riqueza que había que proteger de las manos de las clases pobres: mercancías, stocks, máquinas, etcétera (Foucault, 1986: 113). La distribución espacial y social de la emergente riqueza industrial y agrícola hizo necesarios nuevos controles sociales a finales del siglo XVIII, controles autoritarios y estatales (Foucault, 2003: 52). A partir de entonces, y de modo cada vez más insistente, la penalidad del siglo XIX tiene en vista menos la defensa general de la sociedad que el control y la reforma psicológica y moral de las actitudes y el comportamiento de los 
individuos. El criminal es aquel que perturba la sociedad, el enemigo a perseguir socialmente, independientemente de la ley divina o natural (Foucault, 1986: 93-97). Surge de este modo una red de poder materializado en instituciones, policías, etc., cuya función no es ya castigar las infracciones de los individuos, sino la de corregir sus virtualidades, ejerciendo un control directo y permanente, con la excusa de impedir peligros potenciales (Foucault, 1986: 98).

\section{La sociedad de control: el panoptismo}

Esta orientación del poder demanda la creación de una serie de espacios de control, una especie de topografía del poder que posibilite su efectividad real. El panóptico ideado por Jeremy Bentham en 1791 consiste en un modelo de centro penitenciario cuyo diseño permite a un vigilante observar a los prisioneros desde un lugar central privilegiado, sin que éstos puedan saber si están siendo observados o no (Bentham, 1843: 60-64). Su diseńo se exportó a todo tipo de instituciones que fueron proliferando durante el siglo XIX y que Foucault llama "de secuestro": asilos, escuelas, psiquiátricos... incluso en las fábricas se utilizan estas técnicas de panoptismo para controlar visualmente a todos los trabajadores permanentemente. Estos centros se difunden y complejizan, hasta abarcar de toda la dimensión temporal de la vida de los individuos a través de multitud de instituciones (Foucault, 1986: 129). Para Foucault, la proliferación del panóptico constituye la utopía de una sociedad y de un tipo de poder que se encuentra en el núcleo de la sociedad que actualmente conocemos. Desde entonces el poder ha venido vigilando sin interrupción y totalmente. La red carcelaria, bajo sus formas compactas o diseminadas, con sus sistemas de inserción, de distribución, de vigilancia, de observación, ha sido el gran soporte e insignia, en la sociedad moderna, del poder 
conformador de subjetividades que Foucault llama normalizador (Foucault, 2003: 186).

El panóptico de Bentham sienta el principio de que el poder ha de ser invisible e inverificable, automatizado y desindividualizado (186). Desde entonces se dan las condiciones para el surgimiento de un saber, a partir de dicha observación, que permitirá nuevas formas de control. Esta es la base del saber-poder, que dará lugar a lo que hoy conocemos como ciencias humanas: psiquiatría, psicología, sociología, etcétera (100). Desde estos presupuestos, las leyes acaban siendo ejercidas por las clases altas como modos de control (106). Siempre desde esta posición de inverificabilidad, los nuevos saberes del siglo XIX permiten un campo de acción más completo, desplegado desde un origen espacial exterior hasta el centro íntimo del propio individuo.

Salvando distancias ideológicas y temporales, podemos decir que Max Weber comparte con Foucault una visión realista del derecho, al que circunscribe a un radio de acción de alcance estratégico y de dominio social, tal y como puso de relieve en su obra Economía y sociedad. Para él, las características formales del derecho moderno hacen que resulte apto como medio de organización de los subsistemas de acción racional con arreglo a fines, como solía designar a los cuerpos sociales e instituciones de la contemporaneidad (Weber, 1964). Para Jürgen Habermas, el concepto de derecho de Weber se encuentra sometido a tantos recortes positivistas que, en la búsqueda de la tipificación racional del mismo, parece pasar por alto el aspecto práctico-moral y limitarse a considerar exclusivamente su aspecto cognitivo-instrumental, planificado desde la relación fin-medio y recortado a la medida del tipo de acción que representa la acción estratégica (Habermas, 2003a: 347).

Merece la pena detenerse en esta llamada de atención de Habermas y extrapolarla a la reflexión respecto de estos lugares que hemos caracterizado como "afueras de la justicia", pues nos suscitan 
consideraciones semejantes: pueden interpretarse como el resultado de un uso estratégico de la justicia, con vistas a la prosecución de un fin, que se aplica prácticamente al margen de consideraciones morales. Foucault y Habermas nos describen una moral que ha quedado desinstitucionalizada, subjetivizada y finalmente desplazada por el derecho coactivo que, vaciado de contenidos morales, impone un aplazamiento de la legitimación y posibilita el control de la acción social a través de medios sistémicos (Habermas, 2003b: 255).

Habermas expone cómo el dinero y el poder posibilitan el ejercicio de un influjo estratégico generalizado sobre las decisiones de los otros participantes en las interacciones propias del intercambio social, eludiendo los procesos de formación lingüística del consenso, incluso en las modernas sociedades democráticas. Estos poderes fácticos no sólo simplifican la comunicación lingüística, que considera el foco del que debe partir el consenso social, sino que la sustituyen por una generalización simbólica de perjuicios y compensaciones. De esta forma, el contexto del mundo de la vida, como llama al mundo de la existencia y convivencia real, queda devaluado y dispuesto para interacciones controladas por medios. La masa social acaba desvinculándose de la iniciativa y coordinación de las acciones y degradándose a la categoría de entorno del sistema. Desde la perspectiva del mundo de la vida, el asentamiento contemporáneo de la acción sobre medios de control aparece como una vía para evitar los procesos de entendimiento sobre los que se debería apoyar el consenso social. También se nos muestra como un condicionamiento de las decisiones en un espacio de contingencias ampliado y, en este sentido, como una tecnificación del mundo de la vida (Habermas, 2003b: 400).

Toda dominación burocrático-legal tiene como consecuencia una pérdida de legitimación que, a juicio de Weber, es objetivamente inevitable, pero que subjetivamente es difícil de soportar. 
La acción política queda reducida a la lucha por el ejercicio del poder legítimo hasta la "total eliminación de todo elemento ético en el razonamiento político” (Weber, 1964: 548). De esta forma, la legalidad acaba a la postre basándose en el juicio de aquellos que pueden definir qué es lo que ha de considerarse un procedimiento legal (Habermas, 2003b: 459). Vista en su conjunto, observamos cómo la historia de la política muestra un progresivo aumento de las competencias asumidas por el estado, esto es, un creciente traspaso a él de la responsabilidad paterna: de tal modo que el estado moderno, sea capitalista o socialista, liberal o autoritario, igualitario-democrático o elitista, es cada vez más paternalista en sus efectos (Jonas, 2008: 179).

\section{Uso interesado de preceptos utilitaristas}

Volvamos ahora sobre las consecuencias de lo anteriormente expuesto en nuestros contemporáneos espacios de convivencia social y espacial. En el tratamiento que, desde la esfera dominante de la sociedad, se aplica a los individuos que se salen de los patrones aceptados se puede advertir una puesta en práctica de los preceptos utilitaristas, tal y como fueron expuestos por primera vez por Bentham (2000: 14). Ya hemos visto cómo la reclusión de delincuentes, dementes, ancianos y enfermos incurables en los centros de la sociedad disciplinaria surgidos en el siglo XIX no ha venido persiguiendo, en lo fundamental, ningún tipo de finalidad educativa, de reinserción o recuperación social, ni su curación física o mental. De lo que se trata es de buscar el mayor bien a la mayor parte de la población: la sociedad "sana", que no ha querido cargar o involucrarse con una minoría de inadaptados.

Contemporáneamente, en nuestras actuales ciudades, observamos cómo la práctica urbanística de la zonificación en áreas homogéneas, entre otras prácticas más sutiles, supone la puesta en 
vigor de estos mismos preceptos utilitaristas. El otorgamiento al grupo social principal de las centralidades espaciales y de las mejores ubicaciones implica relegar a los desfavorecidos al extrarradio, donde se agrupan las viviendas sociales en contacto con la periferia industrial y marginal. Podemos, entonces, pensar que los preceptos utilitaristas se acoplan, en cuanto que defienden el mayor bien para el mayor número, a posturas favorables al poder establecido o la mayoría hegemónica, suponiendo así una justificación teórica para la comisión de injusticias para minorías con escasa representación social. El poder se muestra entonces como la injusticia cometida por la mayoría hegemónica legitimada por una coartada utilitarista. John Rawls, uno de los mayores críticos del utilitarismo, siguiendo tanto a Mill como a Sidgwick, seńala que nuestros juicios morales son implícitamente utilitaristas en el sentido de que, al vernos ante una colisión de preceptos o ante nociones que son vagas e imprecisas, no tenemos otra alternativa que adoptarlo (Rawls, 1995: 51).

Respecto a la consideración que merecen estas prácticas, podemos dejarnos llevar por la crítica que hace Rawls del conjunto del utilitarismo, respecto del que recalca que no considera, excepto de manera indirecta, cómo se distribuye la suma de satisfacciones entre los individuos que se pretende conseguir. La distribución correcta en cada caso es la que produce la máxima satisfacción general, sin nunca considerar seriamente la distinción entre personas (37-38). Por otra parte, resulta evidente que no debe importarnos que las leyes, instituciones o prácticas sociales sean eficientes: si son injustas han de ser reformadas o abolidas. Rawls recalca que cada persona posee una inviolabilidad fundada en la justicia que ni siquiera el bienestar de la sociedad en conjunto puede atropellar. Prácticas sociales aceptadas, cómodas de aplicar eludiendo el problema de injusticia social de fondo, no se vuelven justas por el hecho de que produzcan un bien para una mayoría. Es injusto que 
los sacrificios soportados por unos sean compensados por ventajas para otros, aunque sean muchos (17).

\section{Las otras heterotopías}

Ya hemos aludido ligeramente a la existencia de otras heterotopías que, contemporáneamente, cabría añadir a las descritas por Foucault. Se trata de las zonas marginales, centros suburbiales de delincuencia y pobreza, etc. Estos lugares son también los lugares de la delincuencia permanente, arraigada: las periferias de la droga, la prostitución y de todo tipo de delincuencia. Muchas de estas prácticas están asociadas a minorías descolgadas del grupo social hegemónico, hasta el punto de que es inevitable pensar en la existencia de estrategias de autopreservación de privilegios, que relegan a una continua desventaja social a determinados grupos. Teóricamente, los individuos conflictivos socialmente no se encuentran directamente obligados a habitar o frecuentar dichos lugares de marginalidad. Sin embargo, parece pertinente seguir aplicando el enfoque utilitarista para el análisis de estas realidades si consideramos que la mayoría hegemónica puede preferir que la degradación y marginalidad social queden relegadas y restringidas a ámbitos físicos asumidos.

La visión de estas zonas de marginalidad indigna y escandaliza al ciudadano biempensante, pues supone una evidencia del fracaso del ideal, sostenido desde Aristóteles, de ciudad como ámbito privilegiado del buen vivir. Resulta evidente que la estructura social contiene diversos niveles y que los hombres nacidos en posiciones diferentes tienen diferentes expectativas de vida, determinadas, en parte, tanto por el sistema político como por las circunstancias económicas y sociales. Las instituciones de una sociedad favorecen, o se orientan preferentemente, hacia ciertas posiciones iniciales frente a otras. Para Rawls estas desigualdades son especialmente 
profundas y trascendentes, ya que afectan a los hombres en sus oportunidades iniciales de la vida y no pueden ser justificadas apelando a la noción de mérito. Para el pensador norteamericano es a estas desigualdades de la estructura básica de toda sociedad a las que se deben aplicar en primera instancia los principios de la justicia social (Rawls, 1995: 21).

Pero ¿cómo dar una respuesta satisfactoria a las necesidades de integración de estos colectivos? En el repaso crítico de la teoría parsoniana de los medios de control, Habermas señala que sólo los ámbitos de acción que cumplen funciones económicas y políticas pueden quedar efectivamente regulados por medios de control. Sin embargo, estos medios fracasan en los ámbitos de la reproducción cultural, de la integración social y de la socialización. En opinión del pensador de Düsseldorf, en estas funciones de integración social no pueden sustituir al mecanismo del entendimiento como mecanismo coordinador de la acción. Más aún: estos mecanismos de integración socio-cultural no pueden quedar asentados sobre la mera integración sistémica normativa sin que se produzcan efectos laterales patológicos (Habermas, 2003b: 457).

Toda una serie de problemas sociales, desde los proyectos de renovación de áreas urbanas degradadas hasta los proyectos de prevención de la delincuencia, se sumen en la confusión. Todo ello debido, en parte, al uso del control sistémico para la consecución de objetivos que no puede lograr por sí solo (Baum, 1976: 604). De esta forma, podemos hablar de un "abuso" del medio dinero o del medio poder. Los abusos provienen de la falsa percepción de los implicados al pensar que la solución racional de los problemas de control sólo es posible por vía de un comercio y trato, sujeto a cálculo, con el dinero o poder (Habermas, 2003b: 418).

Parece oportuno considerar ahora una reflexión de Hans Jonas que incide en la importancia de dar solución a estas cuestiones: las condiciones que se dan en un orden económico injusto, al igual 
que en un orden político malo, pueden impedir al individuo el "ser bueno" en cualquier sentido (Jonas, 2008: 276). Aquel que no tiene resueltas las primeras necesidades animales se encuentra retenido en un estado premoral. Esto, en la práctica, establece un deber moral para terceros consistente en el esfuerzo por la eliminación del estado de injusticia que impide el acceso a la moralidad de los desfavorecidos (256). Cabe en este punto preguntarse, al igual que Jonas, si los miembros del "primer mundo" privilegiado estarían dispuestos a pagar el precio de la pérdida de parte de sus privilegios en beneficio de un orden social más justo en el que hubiera menos miseria (261) o quizá, como señala Habermas, si en las modernas sociedades es posible, por encima de los mecanismos de control, una forma de entendimiento capaz de coordinar acción a partir del entendimiento y el diálogo sin barreras jerárquicas.

\section{Conclusión}

En nuestras modernas sociedades, el derecho coactivo, que ha venido siendo objeto desde el inicio de la modernidad de un proceso de pérdida de contenidos morales, ha dado lugar a lo que Habermas denomina un aplazamiento de la legitimación, que posibilita el control de la acción social a través de medios sistémicos. Los orígenes de estos mecanismos han sido indagados por Foucault y uno de sus paradigmas más representativos sería el panóptico. Este tipo de control, relacionado con la vigilancia, la homogeneidad, el dinero y el poder, resulta mucho más eficaz y se encuentra más extendido que cualquier intento de formación lingüística del consenso, que sería más propio de un sistema propiamente democrático.

Esta vertebración de la sociedad desde la disciplina origina sistemáticamente toda una serie de problemas y frustraciones en aquellos ámbitos que requieren integración y normalización social 
y educativa. La dificultad en abandonar el rol asignado da lugar a una dinámica en la que determinados grupos se perpetúan en situaciones de desventaja social, poniendo en entredicho el ideal clásico de ciudad como lugar privilegiado de convivencia. Las tramas urbanas, con su división en zonas homogéneas, son el reflejo visible de las gradaciones jerárquicas de la colectividad. La lucha de la sociedad por erradicar estas diferencias no es lo bastante sincera ni contundente, debido al uso interesado de preceptos utilitaristas, que siempre favorecen al grupo mayoritario y socialmente hegemónico, y que se integran bien en la aspiración de homogeneidad del derecho coactivo.

La superación de estas disfunciones es condición previa para integrar a aquellos que se encuentran en el estado premoral que cita Jonas. Para ello, siguiendo a Habermas, es necesario que la sociedad confíe en un mecanismo de entendimiento sin restricciones como coordinador de la acción. Cabe entender que tal tipo de acuerdos son incompatibles con los esquemas de jerarquía, disciplina y control tan implantados en nuestras sociedades, pues su interferencia disipa las posibilidades de un acercamiento sincero. Nos enfrentamos, en definitiva, a la siguiente elección: una sociedad controlada por los mecanismos sistémicos descritos ya por Weber, con riesgos y disfunciones asumidas, o una sociedad abierta a procesos de consenso que integren a todos y nos hagan evolucionar a posiciones en las que todos potencialmente tenemos algo que ganar y que perder.

\section{Bibliografía}

Aristóteles, 1994, Política, C. García y A. Pérez (trad.), Barcelona, Editorial Altaya.

,2001, Ética a Nicómaco, J. L. Calvo (trad.), Madrid, Alianza Editorial. 
Baum, Rainer C., 1976, Introduction to Generalized Media in Action, Nueva York, J.J. Loubser.

Bentham, Jeremy, 1843, Panopticon, Works, Londres, Edición Bowring. ,2000, An Introduction to the Principles of Morals and Legislation, Kitchener, Batoche Books.

Derrida, Jacques, 1995, Khôra, D. Tatián (trad.), Córdoba, Argentina, Alción Editora, disponible en: http://www.jacquesderrida. com.ar/textos/kora.htm

Durkheim, Emile, 1978, De la division du travail social, París, P.U.F.

Foucault, Michel, 1986, La verdad y las formas jurídicas. E. Lynch (trad.), México, GEDISA.

$\longrightarrow$ XXI. 2003, Vigilar y castigar, A. Garzón, Buenos Aires, Siglo

Habermas, Jürgen, 2003a , Teoría de la acción comunicativa. Volumen I: Racionalidad de la acción y racionalización social, M. Jiménez (trad.), Madrid, Editorial Taurus.

,2003b Teoría de la acción comunicativa. Volumen II: Crítica de la razón funcionalista, $M$. Jiménez (trad.), Madrid, Editorial Taurus.

Jonas, Hans, 2008, El principio de responsabilidad, J. M. Fernández (trad.), Barcelona, Herder Editorial S. L.

Rawls, John, 1995, Teoría de la Justicia, M. D. González (trad.), México, FCE-

Weber, Max, 1964, Economía y sociedad, J. Winckelmann (ed.), J. Medina (trad.), México, FCE.

Recibido: 10 de junio de 2016 Aceptado: 3 de noviembre de 2016 